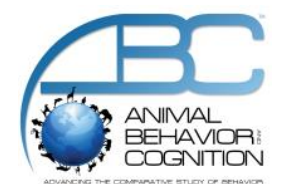

\title{
Pectoral Fin Contact as a Mechanism for Social Bonding among Dolphins
}

\author{
Kathleen M. Dudzinski ${ }^{1, *}$ and Christine A. Ribic ${ }^{2}$
}

${ }^{1}$ Dolphin Communication Project, Florida

${ }^{2}$ U.S. Geological Survey, Wisconsin Cooperative Wildlife Research Unit; University of Wisconsin, Madison, Wisconsin

*Corresponding author (Email: kathleen@dcpmail.org)

Citation - Dudzinski, K. M., \& Ribic, C. A. (2017). Pectoral fin contact as a mechanism for social bonding among dolphins. Animal Behavior and Cognition, 4(1), 30-48. https://doi.org/10.12966/abc.03.02.2017

\begin{abstract}
Bottlenose dolphins are large-brained social mammals residing in a fission-fusion society with relationships that are established and maintained over decades. We examined a decade-long data set of interindividual pectoral fin contact exchanges to better understand how dolphins share information via tactile contact. Sex and age are significant factors in pectoral fin contact within non-kin dolphin dyads. Adult females shared more pectoral fin contacts with other adult females, while younger females showed no pattern of contact. Males shared more pectoral fin contacts with other males as juveniles and as adults, but showed no difference in the number of touches versus rubs as pectoral fin contacts with other males. Whether in the role of initiator as rubber or initiator as rubbee, male dolphins again preferred other males. These results support the notion that dolphins, especially male dolphins, might use pectoral fin contact as one tool in their repertoire for social bonding to establish, maintain and manage their inter-individual relationships. Additionally, it is also likely that the exchange of pectoral fin contact is developed and refined as individuals age, mature socially, and establish their place within a fission-fusion society.
\end{abstract}

Keywords - Pectoral fin contact, Social bonding, Bottlenose dolphins, Tactile contact, Behavior

Most dolphins live in a fission-fusion society characterized by subgroups that frequently change in size and composition throughout the day. In several dolphin groups studied, it would seem that samesex, same-aged pairings represent the primary framework for the fission-fusion society with mixed-sex associations happening, but not as frequently; for example, Atlantic spotted dolphins, Stenella frontalis, in The Bahamas (Dudzinski, 1996; Elliser \& Herzing, 2014; Herzing, 1997; Herzing \& Brunnick, 1997); Indo-Pacific bottlenose dolphins, Tursiops aduncus, around Mikura (Kogi, Hishi, Imamura, Iwatani, \& Dudzinski, 2004) and in Australia (Connor, 1992; Connor, Smolker, \& Richards, 1992); common bottlenose dolphins, T. truncatus, in the USA (Wells, 1991; Wells, Scott, \& Irvine, 1987) and in The Bahamas (Rossbach \& Herzing, 1999). Social tactile contact can be affiliative or agonistic (e.g., Connor, Mann, \& Watson-Capps, 2006; Dudzinski, 1996, 1998), and previous research suggests that at least some dolphins have preferred partners with whom they exchange contact (e.g., Connor et al., 1992; Connor, Mann et al., 2006; Connor, Smolker, \& Bedjer, 2006; Dudzinski, 1998; Herzing \& Brunnick, 1997).

Social contact has been identified as a tool to maintain social relationships in many species, e.g., grooming in lions (Panthera leo, Matoba, Kutsukake, \& Hasegawa, 2013), non-human primates (Goodall, 1986; Majolo et al., 2012; Newton-Fisher \& Lee, 2011), ungulates (Carter, Brand, Carter, Shorrocks, \& Goldizen, 2013), and elephants (Fishlock \& Lee, 2013). Close social associations lead to social bonding 
(Massen, Sterck, \& de Vos, 2010), but understanding how these associations are established and managed among aquatic social mammals such as dolphins is still being clarified.

One way to describe a strong bond between two individuals is by calculating coefficients of association (Cairns \& Schwager, 1987). This method focuses on time spent together as opposed to examining the quality of the interaction (e.g., Kummer, 1978). Another way to examine social bonds between two specific individuals is by examining the exchange of affiliative behaviors as compared to other pairs within a group; exchanging a large number of affiliative behaviors would constitute a strong social bond (Massen et al., 2010). One well-studied example of affiliative behavior used by dolphins is sharing of pectoral fin contact (e.g., Connor, Mann et al., 2006; Dudzinski, Gregg, Ribic, \& Kuczaj, 2009; Dudzinski, Gregg, Paulos, \& Kuczaj, 2010; Dudzinski et al., 2012; Dudzinski, Danaher-Garcia, \& Gregg, 2013; Johnson \& Moewe, 1999; Mann \& Smuts, 1998; Paulos, Dudzinski, \& Kuczaj, 2007; Sakai, Takeda, \& Kohshima, 2006a, b).

Affiliative behaviors, especially tactile contact among dolphins, could be considered one form of currency used in the development of social bonds (Cords, 1997); many smaller delphinid species reside in fission-fusion societies (Kogi et al., 2004; Smolker, Richards, Connor, \& Pepper, 1992; Wells et al., 1987). Small subgroups will mix to form larger groups for foraging or other activities before separating again into the same or different subgroups (Aureli et al., 2008), with this multi-level socializing requiring complex cognitive abilities to keep track of individuals with whom one is familiar or not (Connor \& Mann, 2006). In playback experiments, Bruck (2013) confirmed that bottlenose dolphins exhibit longterm social memory lasting almost two decades: dolphins exhibited behavioral recognition of whistles from conspecifics not encountered in 20 years or more. In some regions, male bottlenose dolphin dyads, and triads, form alliances that last for years, if not the life of the individuals (Connor et al., 1992; Connor \& Krützen, 2015). Alliances are often formed among genetically unrelated males and the subtle intricacies with respect to how these relationships are established and maintained for years is less well understood for dolphins as compared with terrestrial or avian species (e.g., Fraser, Schino, \& Aureli, 2008; Fraser \& Bugynar, 2010). Affiliative tactile behavior, e.g., pectoral fin contact, might offer clues as to how dolphins first establish and then maintain their social relationships over time.

Our initial studies focused on signal exchange between individuals from two distinct groups of wild dolphins in The Bahamas and around Mikura Island, Japan (e.g., Dudzinski, 1998; Gregg, Dudzinski, \& Smith, 2007; Paulos et al., 2007). After more than a decade of focus on wild dolphins, we were offered the opportunity to apply our methodology to a captive dolphin group while continuing studies on wild dolphins. Thus, we were able to apply the same methodology to data collection and data analyses at all study sites (both wild and captive). Since 2003, we have been studying how individual dolphins, from both captive and wild settings, exchange pectoral fin contacts, and several interesting shared patterns among groups have emerged. Overall, rates of contact were not different between dolphin dyads in different habitats (Dudzinski et al., 2010). Where and how dolphins use pectoral fin contact was also conserved between individuals of different species, in different geographies, and for wild and captive dolphins (Dudzinski et al., 2009, 2010, 2013). However, when examining how vocal behavior was associated with pectoral fin contacts, initiators whistled with pectoral fin contact twice as often as receivers, whereas receivers produced more than double the amount of click trains and all overlap vocalizations with pectoral fin contact (Evans-Wilent \& Dudzinski, 2013). Whereas our previous studies presented a comparative perspective on pectoral fin contact exchanges, our most recent research focuses on one population of bottlenose dolphins (Tursiops truncatus) at the Roatan Institute for Marine Sciences (RIMS) on Roatan Island, Honduras. Our current goals were to elucidate potential function(s) of pectoral fin contact as it is exchanged between different aged and sexed dolphins, between kin and non-kin individuals and to elucidate individual patterns of use, and the potential social functions of pectoral fin contacts.

Two questions drove the current study: 1) excluding mother/calf dyads (which are the focus of another set of research questions), might kinship affect the frequency of exchange of pectoral fin contact within dyads? And, 2) do dolphins engage in immediate reciprocity of pectoral fin contacts and, if so, what differences in immediate reciprocity might be related to sex, age, and/or partner preference for the 
initiating and receiving dolphins? The RIMS study group is particularly suited to addressing these questions. We have more than 13 years of annual observations yielding extended underwater sessions on specific individual dolphins and their dyadic interactions available for analysis. Additionally, nine matrilines including two second-generation mothers reside in this group; thus, an examination of kin dyads and kin versus non-kin dyads with respect to pectoral fin contact exchanges, from the sibling perspective, is possible because, in general, there were at least three siblings per adult female within the group on any given year.

Signals are often context dependent and modified by other factors (e.g., posture or age); for example, chases, bites, and kicks are actions used by dolphins during aggression but are interpreted as play when approach is made at oblique angles with indirect postures (Dudzinski, 1998). As such, three alternative hypotheses were considered to clarify the potential function of pectoral fin contact as a behavioral tool available to dolphins during social activity (see summary of alternative hypotheses in Table 1).

\section{Alternative Hypotheses}

Hypothesis 1 - Social Bonding. Dyads with strong social bonds are characterized by disproportionately frequent affiliative behaviors as compared to other pairs within the same group. The social bonding hypothesis suggests that group-living animals should use potentially risky interactions to regularly reinforce affiliative relationships (Zahavi, 1977). Dolphins engage in agonistic behaviors during socio-sexual and play activities that could result in serious injuries (Dudzinski et al., 2003; Harvey, 2015; Östman, 1991; Overstrom, 1983). We postulate that dolphins have a mechanism to mitigate these agonistic actions and propose the following predictions to address this hypothesis.

Social bonding - Prediction 1. Pectoral fin contact will be more frequent in same-sex, same-aged dyads rather than mixed-sex, mixed-age dyads because wild bottlenose dolphin groups are typically observed in same-sex groups (e.g., Connor, Smolker et al., 2006; Rossbach \& Herzing, 1999; Smolker et al., 1992; Wells et al., 1987). Thus, mixed-sex groups are more prevalent as larger assemblages during heightened social activity but are less stable than same-sex groups (Connor, Smolker et al., 2006; Smolker et al., 1992; Wells et al., 1987).

Social bonding - Prediction 2. Pectoral fin contact will be more frequent among non-kin than kin because kin recognize each other with other mechanisms so pectoral fin contact could be used less frequently (Table 1). Bruck (2013) confirmed that dolphins are capable of long-term social memory spanning decades, and other researchers have found via numerous studies that bottlenose dolphins readily recognize and react to playbacks of the signature whistles of familiar, even related, individuals (e.g., Janik, Sayigh, \& Wells, 2006; King, Harley, \& Janik, 2014; Sayigh, Esch, Wells, \& Janik, 2007). For many species, kin recognition has been documented for aquatic mammals between mother and offspring, siblings, and second-generation relations via visual, vocal and olfactory cues (e.g., Sauvé, Beauplet, Hammill, \& Charrier, 2015; Trimble \& Charrier, 2011; Wilson et al., 2015), non-kin require social mechanisms or tools to establish and maintain a social relationship with a new conspecific.

Social bonding - Prediction 3. Pectoral fin contact is immediately reciprocal. Dolphins have been identified as reciprocal altruists (Connor, 1995; Connor \& Norris, 1982); as defined by Trivers (1971), reciprocity of altruistic behaviors functions outside of genetic relatedness and likely arises via learning. Epimeletic behavior, social structure with relationship fluidity, and both intergeneric and interspecific cooperative behaviors have been both anecdotally and rigorously documented for several delphinds (e.g., Anderson, 1969; Connor, Mann et al., 2006; Connor, Smolker et al., 2006; Simard \& Gowans, 2004; Smolker et al., 1992; Tavolga \& Essapian, 1957). A society with reciprocal altruism allows for the development of complicated social relationships with social rules and complicated communication systems between group members. Thus, we predict that immediate reciprocity will be greater between same-sex, same-aged pairs rather than between mixed-sex, -aged dyads (Table 1). Additionally, more pectoral fin contact exchanges would be expected between non-kin than between kin under the assumption that pectoral fin contact is used to maintain social bonds between unrelated individuals. 
Hypothesis 2 - Expression of Social Status. Dominance ranks and hierarchies are often identified in terrestrial social mammals (de Waal, 1989; Smuts, Cheney, Seyfarth, Wrangham, \& Struhsaker, 1987; Trivers, 1985) and have been confirmed for marine mammals, especially pinnipeds (e.g., Young, González-Suárez, \& Gerber, 2008). Intra-group affiliative and agonistic behaviors are often distributed in relation to rank and indicate a dominant or subordinate position within the community. Only a few studies have provided evidence for linear dominance hierarchies among mostly captive dolphins (Östman, 1991; Samuels \& Gifford, 1997); rather, the social structure of studied dolphin groups has been compared more to a complex web with individuals possessing differing association strengths with conspecifics within and across several subgroups (e.g., Lusseau, 2003; Lusseau et al., 2006). The lack of evidence for consistent dominance hierarchies could be related to sample size. That is, multi-year, detailed, lengthy observations of inter-individual interactions are available only from a few wild study populations (e.g., Connor \& Krützen, 2015; Dudzinski et al., 2009; Elliser \& Herzing, 2014; Kogi et al., 2004; Wells et al., 1987). Assuming dolphin social structure includes some level of dominance hierarchy, specific tactile affiliative behavior(s) might function as a tool to mitigate interactions to reinforce the relationship status among individuals in a group. Different assumptions about social status lead to different predicted patterns in pectoral fin contact exchange.

Expression of social status - Predictions. Under the assumption that pectoral fin contact serves as a dominance assertion then we predict more male to female initiation of this behavior rather than the reverse and more mixed-sex interactions rather than same-sex exchanges (Table 1). Also, if pectoral fin contact serves to indicate dominance, we would expect more adults initiating pectoral fin contact toward younger (subadults, juveniles or calves) dolphins. If, on the other hand, pectoral fin contact signals submission, then we predict more female to male initiation of contacts rather than the reverse. And, we would also expect younger dolphins to initiate pectoral fin contacts with older dolphins. Taken together, these predictions (e.g., male to female, adult to younger individual) would relate to directional exchanges of pectoral fin contact between individuals that would be expected as an expression of a dominance hierarchy as is seen in many primates (Wakefield, 2013). Also analogous to the directionality of grooming documented for chimpanzees and other primates (Wakefield, 2013), pectoral fin contact would not be immediately reciprocal and the recipient would be assumed to be more dominant to the initiator. Both dominance and submission predict unidirectional exchanges of tactile behavior. For the Social Status Hypothesis to be applicable as an explanation of the function(s) of pectoral fin contact exchange, immediate reciprocity would not be expected to be equally distributed or consistently observed within same-sex, same-aged pairs and would be typically more documented by one sex to the other in the mixedgender pairs. Pectoral fin contact exchanges would be predicted to be more common between kin than non-kin as dominance hierarchies when observed are often inherited (e.g., primates, Goodall, 1986), and pectoral fin contact in this case could be considered an indicator of status shared by kin.

Hypothesis 3 - Tension Reduction. Social stress originates from instability in inter-individual relationships that can disrupt the cohesion in a group; competition for access to resources and reunions after separations of varying length (e.g., lions, Matoba et al., 2013) are examples of contexts that might foster tension or competition. Natural selection should favor development of signals that communicate a non-agonistic intent; greeting behaviors provide for relationship updates after separations for many species, for example, primates (Aureli et al., 2008; de Waal, 1989; Goodall, 1986), hyenas (Smith et al., 2011), and dolphins (Connor, Mann et al., 2006; Dudzinski, 1998; Dudzinski et al., 2009; Sakai et al., 2006a). Tension might also arise between younger individuals when play gets too boisterous. These young might seek consolation from an adult or other peers via tactile contact to reassure them of their bond while also reducing stress.

Tension reduction - Predictions. We predict that pectoral fin contact will vary more in duration and expression (age/sex) between touches (static contact) and rubs (active motion between rubber and rubbee). That is, we assume agonistic interactions might be greater between mixed-sex, -age pairs thus requiring a mechanism to diffuse a situation (Table 1). Longer, more active movement (i.e., rub) contacts could provide that mechanism. Additionally, we predict that the initiating dolphin will more often assume the role of rubbee and the rubbee is more likely to present a more sensitive body part (e.g., face, belly, 
genital area, Ridgway \& Carder, 1993) to solicit contact that might function as a tension reduction mechanism. That is, solicitation of contact on a sensitive body part would support a function of tension reduction for pectoral fin contact exchanges. Pectoral fin contact would not be expected to be immediately reciprocal but would be unidirectional if the primary function were a reduction of tension(s). Finally, we predict more pectoral fin contact exchanges between non-kin rather than between kin dyads because non-kin would require a mechanism outside of familial recognition to potentially mitigate behavioral interactions that could escalate into an agonistic or aggressive altercation.

Table 1

Brief Summary of Alternative Hypotheses and Related Predictions Examined to Explore the Functionality of Pectoral Fin Contact Exchanges between Dolphins

\begin{tabular}{|c|c|c|}
\hline Hypothesis & Predictions & $\begin{array}{l}\text { Expected Patterns - } \\
\text { kin vs. non-kin }\end{array}$ \\
\hline 1. Social Bonding & 1a. pfc is more frequent in SS/SA pairs & \multirow[b]{2}{*}{$\begin{array}{l}\text { pfc is more frequent } \\
\text { between non-kin than } \\
\text { between kin }\end{array}$} \\
\hline $\begin{array}{l}\text { group-living animals should use } \\
\text { potentially risky interactions to } \\
\text { reinforce affiliative relationships }\end{array}$ & $\begin{array}{l}\text { 1b. pfc is more frequent between non-kin than kin } \\
\text { 1c. pfc is exchanged IR more between SS/SA rather } \\
\text { than DS/DA pairs }\end{array}$ & \\
\hline 2. Expression of Social Status & $\begin{array}{l}\text { 2a. M-to-F initiated pfe is greater than F-to-M } \\
\text { initiated pfc }\end{array}$ & \multirow{3}{*}{$\begin{array}{l}\text { pfc is more frequent } \\
\text { between kin than non- } \\
\text { kin }\end{array}$} \\
\hline $\begin{array}{l}\text { if dolphin society includes a } \\
\text { hierarchy, tactile behavior(s) } \\
\text { might serve to mitigate }\end{array}$ & $\begin{array}{l}\text { 2b. older dolphins initiate more pfc to younger } \\
\text { dolphins than reverse }\end{array}$ & \\
\hline $\begin{array}{l}\text { interactions \& reinforce status in } \\
\text { a group }\end{array}$ & 2c. pfc is not IR & \\
\hline 3. Tension Reduction & $\begin{array}{l}\text { 3a. pfc varies in duration } \& \text { age/sex for touches vs. } \\
\text { rubs }\end{array}$ & \multirow{4}{*}{$\begin{array}{l}\text { pfc is more frequent } \\
\text { between non-kin than } \\
\text { kin }\end{array}$} \\
\hline \multirow[t]{3}{*}{$\begin{array}{l}\text { behaviors might be used to signal } \\
\text { a non-agonistic intent, e.g., at } \\
\text { greeting, after/during aggressive } \\
\text { play }\end{array}$} & $\begin{array}{l}\text { 3b. body part contacted correlated with easing tension } \\
\text { (e.g., sensitive anatomy (e.g., face) would be } \\
\text { contacted more to ease tension) }\end{array}$ & \\
\hline & $\begin{array}{l}\text { 3c. pfc INI dolphin contacts similar body parts when } \\
\text { in role of rubbee and rubber }\end{array}$ & \\
\hline & 3d. pfc is not IR & \\
\hline
\end{tabular}

Note. See text for additional details. Abbreviations in the table include: $\mathrm{pfc}=$ pectoral fin contact; SS/SA = same-sex, same-aged; $\mathrm{DS} / \mathrm{DA}=$ different sex, different aged; IR = immediately reciprocal pfc exchanges; $\mathrm{M}=$ male; $\mathrm{F}=$ female; INI $=$ initiating; rubbee is dolphin whose body is in contact with a rubber's pectoral fin (for definition details see Dudzinski et al., 2009).

\section{Current Study Objectives}

The current study examined the exchange of pectoral fin contact behaviors between dolphin dyads from a group of captive bottlenose dolphins observed for more than a decade. We used this multi-year data set to address predictions stemming from our alternative hypotheses (see Table 1). Our objective was to examine in detail how dolphins share this tactile contact. With whom do these dolphins predominantly exchange contacts; is there partner preference based on gender or age? Are there changes (behavioral and/or social) over time in how dolphins use their pectoral fins to share contact with conspecifics? Could pectoral fin contact serve as a behavioral tool to establish, maintain and mitigate social relationships among these bottlenose dolphins? 


\section{Method}

Data were collected as part of a longitudinal, comparative examination of dolphin signal exchange by the Dolphin Communication Project (e.g., Dudzinski et al., 2009, 2010; Evans-Wilent \& Dudzinski, 2013; Paulos et al., 2007). Permission to collect data on the dolphins at the Roatan Institute for Marine Sciences (RIMS), Anthony’s Key Resort (AKR), Roatan, Honduras, was granted by the facility.

Table 2

Effort, Population Demographics and Pectoral Fin Contacts Documented Per Year of Data Collection at RIMS, AKR, on Roatan, Honduras

\begin{tabular}{|c|c|c|c|c|c|}
\hline Year & Effort (min.) & $\begin{array}{c}\text { Group } \\
(N) \\
\end{array}$ & F:M & $\begin{array}{c}\mathrm{F}: \mathrm{A}, \mathbf{S}, \mathbf{J}, \mathrm{C} \\
\mathrm{M}: \mathrm{A}, \mathrm{S}, \mathrm{J}, \mathrm{C}\end{array}$ & Pec. Fin CNT $(N)$ \\
\hline 2003 & 2,173 & 18 & $9: 9$ & $\begin{array}{c}\text { F: } 6,0,1,2 \\
\text { M: } 2,3,3,1\end{array}$ & 1,027 \\
\hline 2004 & 706 & 17 & $8: 9$ & $\begin{array}{l}\mathrm{F}: 5,0,2,1 \\
\mathrm{M}: 2,1,3,3\end{array}$ & 195 \\
\hline 2005 & 392 & 19 & 10:9 & $\begin{array}{c}\text { F: } 6,0,2,2 \\
\text { M: } 2,1,3,3\end{array}$ & 149 \\
\hline 2006 & 568 & 16 & $8: 8$ & $\begin{array}{l}\text { F: } 6,0,1,1 \\
\text { M: } 2,2,0,4\end{array}$ & 242 \\
\hline 2007 & 413 & 18 & $9: 9$ & $\begin{array}{l}\text { F: } 6,0,1,2 \\
\text { M: } 1,2,3,3\end{array}$ & 53 \\
\hline 2008 & 232 & 19 & $10: 9$ & $\begin{array}{l}\mathrm{F}: 5,2,2,1 \\
\mathrm{M}: 2,3,2,2\end{array}$ & 99 \\
\hline 2009 & 650 & 23 & $12: 11$ & $\begin{array}{l}\mathrm{F}: 7,0,2,3 \\
\mathrm{M}: 4,2,2,3\end{array}$ & 355 \\
\hline 2010 & 652 & 23 & $11: 12$ & $\begin{array}{l}\text { F: } 7,1,2,1 \\
\text { M: } 4,2,4,2\end{array}$ & 645 \\
\hline 2011 & 373 & 26 & $13: 13$ & $\begin{array}{l}\text { F: } 7,2,1,3 \\
\text { M: } 6,0,4,3\end{array}$ & 163 \\
\hline 2013 & 335 & 19 & $12: 7$ & $\begin{array}{l}\mathrm{F}: 7,0,1,4 \\
\mathrm{M}: 4,0,0,3\end{array}$ & 94 \\
\hline Totals: & 6,494 & & $19: 22$ & & 3,022 \\
\hline
\end{tabular}

Note. Abbreviations include $\mathrm{F}=$ female, $\mathrm{M}=$ male, $\mathrm{A}=$ adult, $\mathrm{S}=$ subadult, $\mathrm{J}=$ juvenile, $\mathrm{C}=$ calf, Pec. $=$ pectoral, and $\mathrm{CNT}=$ contact.

\section{Study Site and Population}

For this study, data were gathered at RIMS annually from 2003 to 2013. The dolphins reside in sea pens located inside Roatan's fringing reef in a natural lagoon; the main enclosure encompasses roughly $8,000 \mathrm{~m}^{2}$ in surface area. Because of the large enclosure, this dolphin group has ample space for individuals to choose with whom to or not to interact; adult males and adult females often remain in the same large enclosure but do not routinely interact with one another on a daily basis. And, the dolphins are able to maintain a seasonal breeding pattern during which the males often remain within $2-3$ body lengths of a cycling adult female and refuse to participate in programs (Teri Bolton, personal communication, 2015). Members of this bottlenose dolphin population ranged in age from neonate to 30+ years; the general social dynamic was similar to that observed for wild bottlenose dolphins (e.g., Kogi et al., 2004). Additionally, age and sex distribution for the group matches most coastal wild bottlenose dolphin study groups with the size of this study population ranging annually between 16 and 26 dolphins 
(Table 2; total number of dolphins varied depending on managed movement between other facilities managed by RIMS, as well as by recorded deaths and births). A total of 41 individually identified dolphins (19 females, 22 males) were observed.

\section{Data Collection}

A mobile video/acoustic system that permits real-time synchronous video and stereo audio recordings under water was used to document dolphins from an underwater perspective (Dudzinski, Clark, \& Würsig, 1995). Swims were video-documented in 30 or $60 \mathrm{~min}$ sessions opportunistically with limiting factors including poor weather, sea, and visibility conditions. From videotapes, pectoral fin contact behavior data were collected using focal animal and event sampling (Altmann, 1974; Mann, 1999). Follows and recordings of dolphins began as soon as the video camera and observer were in position and group composition was assessed. An individual was selected and recorded until it was no longer within the field of view. Pectoral fin contact behavior was coded only from video data.

Table 3

Sample Sizes of Pectoral Fin Contact (CNT) Events and Immediately Reciprocal Contacts (IR) for Kin (Through the Maternal Line) and Non-Kin Dyads by Sex and Age Class

\begin{tabular}{|c|c|c|c|c|c|c|}
\hline - & \multicolumn{2}{|c|}{$\begin{array}{l}\text { Contacts } \\
(\text { CNT })\end{array}$} & \multicolumn{4}{|c|}{$\begin{array}{l}\text { Immediately Reciprocal } \\
\text { (IR) }\end{array}$} \\
\hline & Kin & Non-kin & Total & Kin & Non-kin & Total \\
\hline $\begin{array}{l}\text { Female } \\
(\boldsymbol{n}=\mathbf{1 7})\end{array}$ & 24 & 342 & 367 & 10 & 46 & 56 \\
\hline $\begin{array}{l}\text { Male } \\
(n=\mathbf{2 0})\end{array}$ & 150 & 875 & 1,024 & 11 & 128 & 139 \\
\hline subtotals & 174 & 1,217 & 1,391 & 21 & 174 & 195 \\
\hline Calf & 126 & 284 & 410 & 9 & 30 & 39 \\
\hline Juvenile & 36 & 467 & 503 & 12 & 63 & 75 \\
\hline Subadult & 1 & 258 & 259 & $--*$ & 37 & 37 \\
\hline Adult & 11 & 208 & 219 & $--*$ & 44 & 44 \\
\hline subtotals & 174 & 1,217 & 1,391 & 21 & 174 & 195 \\
\hline
\end{tabular}

Note. Sample size for pectoral fin contacts is representative of the initiator (INI) role in the tactile exchange. Age class definitions provided in the text. *-- for the adult and subadult age classes in the IR kin category indicates there were no kin available in these categories following the matriline application for kin determination.

Each contact event between one dolphin's pectoral fin and another dolphin's body (including the pectoral fin) was documented (CNT) (Table 3). Other recorded information included: date of occurrence, "real" time of contact, initiating dolphin identification, age and sex, receiving dolphin identification, age and sex, each dolphin's posture, duration of contact, and whether contact was a touch or rub. In addition, whether the initiating and receiving dolphins were the rubber or rubbee (see definitions below), and which body part was contacted on the rubbee were documented (For a diagram depicting body part labels, see Figure 1.).

\section{Definitions}

Because this paper represents a comprehensive examination of individual patterns and development of exchanges of pectoral fin contact between dolphins, several definitions were followed that are consistent with those previously presented in the literature (Dudzinski et al., 2009, 2010, 2012, 2013). Pectoral fin contact exchanges (CNT) were begun by one dolphin, either the rubber or rubbee, approaching and physically contacting another dolphin and were ended by one dolphin departing or both dolphins simply separating from contact. To clarify: the rubber is, by definition, the dolphin whose pectoral fin is in contact with another dolphin's body. This second dolphin is referred to as the rubbee 
because any part of its body is in contact with the other dolphin's pectoral fin (Dudzinski et al., 2009). Still, either rubber or rubbee can initiate or receive contact (Dudzinski et al., 2009). Dolphin body parts can be roughly divided into sensitive areas (e.g., face, rostrum, genital area, belly) and those that might be considered less sensitive with functional differences when contacted (e.g., pectoral fin, peduncle, back). Ridgway and Carder (1993) mapped dolphin skin sensitivity based on somatosensory evoked potentials confirming their most sensitive areas were around the eyes, the rostrum and melon with the flank and back least sensitive to vibrations and pressure changes (the genital area and "belly" were not tested). Other definitions (e.g., postures) are also consistent with previously published work on this study group and topic (Dudzinski et al., 2009, 2010, 2012, 2013).

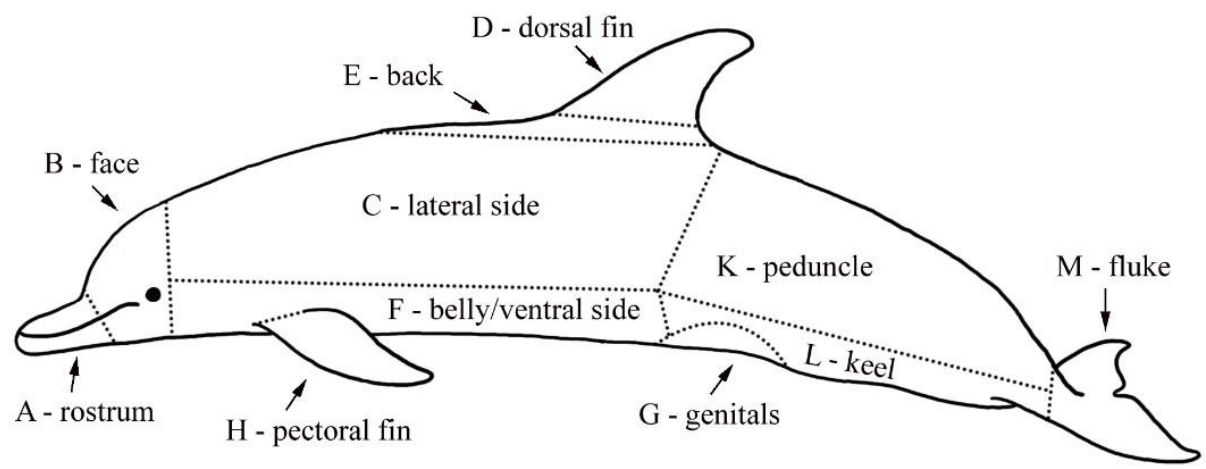

Figure 1. Diagram of the dolphin body with body parts identified during this study labeled (with permission from Dudzinski et al., 2009).

Four dolphin age classes [i.e., adult ( $2 \mathrm{~m}$ long), subadult ( $\sim 3 / 4$ length of adult with less girth), juvenile ( $\sim 1 / 2$ adult length) and calf (less than $1 / 2$ length of adult)] were identified to categorize dolphins at RIMS and were based on knowledge of the year born (from RIMS records, E. Bolton, RIMS Director, personal communication to KMD, 2013) or age estimation if wild-caught based on size and girth in comparison to literature for other bottlenose dolphin study populations (e.g., Connor, Smolker et al., 2006; Kogi et al., 2004). Kin relations were assessed based on maternal relatedness - paternity was not assessed for this study group; therefore, examination of pectoral fin contact exchanges between siblings was based on matrilineal lines. (Note on paternity: Male and female dolphins are not separated during crepuscular and nighttime hours. As such, adult males have access to cycling females and paternity has not been ascertained via blood samples as yet.)

Immediate reciprocity in this study related only to exchanges of pectoral fin contact within a dyad that adhered to the following criteria:

1) one dolphin initiated a pectoral fin contact (as either rubber or rubbee) to a second, receiving dolphin, and

2) after contact was complete, but before either dolphin left the observer's field of view, each other's view, or interacted with a third dolphin, the receiver returned a pectoral fin contact to the initiating dolphin.

No specific time frame for an immediately reciprocal (IR) exchange was identified, though the time between reciprocal exchanges was typically not longer than $25-30 \mathrm{~s}$.

\section{Statistical Analyses}

The focus of analysis was the initiator dolphin (i.e., the sampling unit). The data for each initiator dolphin were the set of pectoral fin contact exchanges combined over all sampling years (2003 - 2011, 2013) categorized by sex (same/different: SS is same sex, DS is different sex) and age class (same/different: SA is same age, DA is different age). We were interested in individual variation within the sex and age classes as well as overall differences between the sex and age classes. 
In order to look at both individual patterns and overall class patterns, we used a contingency table approach that accounts for the multiple observations made on the initiator dolphin. In standard contingency tables, only one observation is made on each independent sampling unit, in our case, the initiator dolphin. However, we have multiple observations on the initiator dolphins and simply pooling results across individuals to assess sex-based differences will generally yield a misleading result. Therefore, we used the approach in Garson and Moser (1995) as implemented in TableSim (Rugg, 2003). We present a brief explanation of the analysis technique here as applied to the dolphin data. Please see Garson and Moser (1995) for details on the aggregation problem in ecology and Rugg (2003) for program implementation details. The analysis is based on the idea of there being more variability across initiator dolphins within a population of interest (e.g., male, female) than is accounted for in the multinomial model used to derive the standard Chi-square test. The individual data (e.g., initiator dolphin data categorized into same sex/same age, same sex/different age, different sex/same age, different sex/different age categories) are used to estimate the parameters of a Dirichlet distribution with mean vector $\pi j$ (the true mean vector of category probabilities for population $\mathrm{j}$ ) and scale parameter $\gamma \mathrm{j}$ (a measure of variability). When the scale parameter is small, the response probability distribution is not well determined and can vary across individuals; when the scale parameter is at its maximum, there is no extra variability, so the individual response distribution is always the population response distribution. The estimates of the scale parameter are used to compute weights, $\alpha \mathrm{j}$, which are used to properly pool the population response distributions into an overall average distribution, $\pi$. To generate the null distribution of the test statistic, the program sets $\pi$, rather than $\pi \mathrm{j}$, as the center of the Dirichlet distribution, while the scale parameters remain population-specific. Random response distributions for the initiator dolphins from each population are created, and then an appropriate number of observations are generated for each dolphin using those distributions. The test statistic takes the form of a chi-square test statistic and we used 20000 Monte Carlo simulations for each test to determine significance. We then used residual analysis (Lloyd, 1999) to understand the individual variation within the sex/age categories.

We used a generalized linear mixed effects model (Pinheiro \& Bates, 2009) with an interaction to determine if duration of pectoral fin contact differed by touch/rub and sex of pair or age of pair. The initiating dolphin was a random effect and we used a Gaussian error structure. We used the statistical package R (version 2.15.3) for the mixed model analyses. For all analyses, we used an alpha of 0.05 for significance and 0.10 for trends. For the residual analysis, we used positive residuals greater than 1.96 (alpha of 0.05) to determine where more interactions than expected occurred.

\section{Results}

Over 10 years of observation of tactile exchanges within bottlenose dolphin dyads at RIMS, a total of 3,022 pectoral fin contacts was documented between kin (through the maternal line, hereafter maternal kin) and non-kin pairs (Table 2). Removing contacts for which identity of the initiator and/or receiver was not confirmed yielded a total sample of 1,391 pectoral fin contact events, 1,217 for non-kin dyads and 174 for maternal kin dyads across both sexes and four age classes (Table 3). Of the total contacts for which the initiator was known, only 195 contacts were immediately reciprocated (Table 3 ).

\section{Non-Kin Contacts - Sex Variation}

Females differed in their interactions among the sex/age categories, $\chi^{2}(4, n=343)=226.06$, $p<0.001$, for non-kin pectoral fin contact patterns. Of the 17 initiator females, 13 had preferences with whom they interacted (residual analysis, $p<0.05$ ). Seven females interacted significantly more often with other females of the SA. Specifically, adult females exchanged contacts with other adult females, and though a preference for specific partners was observed between dyads, there did not seem to be a hierarchy among these adult females. That said, adult females generally shared more pectoral fin contact with other adult females only after having their first calf. Three females interacted significantly more with 
other females of a DA, two females interacted significantly more with males of the SA, and one female interacted significantly more with males of a DA.

Males also differed in their interactions among the sex/age categories, $\chi^{2}(4, n=873)=379.11, p$ $<0.001$ for non-kin pectoral fin contact patterns. Of the 20 initiator males, 14 had preferences with whom they interacted (residual analysis, $p<0.05$ ). Three males interacted significantly more with other males of the SA, four males interacted significantly more with other males of a DA, four males interacted significantly more with females of the SA, and three males interacted significantly more with females of a DA. These results support Social Bonding, prediction 1a (Table 1). The adult male (Paya) considered by trainers to be the "alpha" for this group was not observed sharing much pectoral fin contact with other adult males (he was one of the males that interacted more with males of a DA), while males in the younger age classes shared more contact with preferred partners but not seemingly along a hierarchy of individuals. When looking at the identified individuals and with whom they shared contact, there was no clear pattern exhibited by all of the adult males or all of the younger males. For example, Anthony, Han and Ken were the males that shared contact with same aged males though Han is an adult and Anthony and Ken are juveniles or subadults depending on the year of study.

Overall, males and females had different age/sex contact patterns, $\chi^{2}(4, n=1,216)=10.17, p=$ 0.0125 . Specifically, males initiated more than $77 \%$ of all their contacts with other males and most with males of DA (44\%). Female initiators showed little sex-contact bias with $45 \%$ of the contacts being with females and $55 \%$ with males, but females did initiate more contacts with individuals of a DA (62\% of female-initiated contacts were with animals of DA). These results support Social Bonding, prediction 1a and refute Social Status 2, prediction 2a (Table 1).

\section{Non-Kin Immediate Reciprocity (IR) - Sex Variation}

The data are much more sparse for non-kin IR of pectoral fin contacts but it is still possible to examine exchanges for patterns within and between the sexes. Within both sexes, individuals varied with what sex/age classes they interacted (females, $\chi^{2}(4, n=46)=68.35, p=0.0002$; males, $\chi^{2}(4, n=128)=$ $83.95, p=0.002)$. Of the 13 initiator females involved in IR exchanges, only six had sex/age class preferences for IR exchanges (residual analysis, $p<0.05$ ). Two females had IR exchanges significantly more with other females of the SA, two females had IR exchanges significantly more with other females of a DA, and one female each had IR exchanges significantly more with males of the SA and with males of a DA. Of the 16 initiator males involved in IR exchanges, only seven had sex/age class preferences for IR exchanges (residual analysis, $p<0.05$ ). Two males had IR exchanges significantly more with other males of the SA, two males had IR exchanges significantly more with females of the SA, and three males had IR exchanges significantly more with females of a DA.

Overall, IR pectoral fin contacts (in terms of sex/age categories) tended to be different between the sexes, $\chi^{2}(4, n=174)=6.20 ; p=0.092$. Males tended to have more IR interactions with males $(33 \%$ SA, $48 \%$ DA) while females tended to have more IR interactions with females of the SA (39\%) and males of a DA $(30 \%)$.

Generally, the significantly larger documented sample of non-kin contacts $(N=1,217)$ as compared with maternal kin-exchanged $(N=174)$ pectoral fin contacts supports Social Bonding (prediction 1b) and Tension Reduction, but not Social Status (Table 1). Similarly, from all contacts documented, only 195 were IR, which would seem to suggest support for Social Status (prediction 2c) and Tension Reduction (prediction 3d); however, of these IR pectoral fin contacts $(N=195)$ more were exchanged between non-kin $(n=174)$ than kin $(n=21)$, which lends support to Social Bonding, prediction 1c (Table 1).

\section{Non-Kin Contacts - Age Class Variation}

Sample sizes allowed for an examination of differences between the sexes for juveniles, sub- 
adults and adults with respect to non-kin pectoral fin contacts. Juvenile females and males had different patterns of interaction, $\chi^{2}(4, n=466)=16.10, p<0.001$. Specifically, juvenile females interacted with every sex/age class (DS/SA: 27\%; SS/DA: 35\%; DS/DA: 29\%) except for other juvenile females (9\%) while juvenile males interacted more with other males (81\%) than females (19\%), regardless of age. Subadult females and males also had different patterns of interaction, $\chi^{2}(4, n=258)=17.25, p<0.001$. Subadult females interacted more often with non-sub-adult males (68\%), whereas sub-adult males interacted more with DA males $(82 \%)$. Adult males and females had the same pattern of interaction, $\chi^{2}(4, n=209)=$ $4.68, p=0.18$. Adults interacted mainly with other adults of the SS (45\%), rather than with younger dolphins of the SS (30\%) followed by interactions with younger dolphins of a DS (15\%) and adults of a DS (11\%). These results generally support Social Bonding, prediction 1a while refuting Social Status, prediction $2 \mathrm{~b}$ (Table 1).

Seven individuals initiated contacts as juveniles and subadults and six individuals initiated contacts as juveniles and adults. There were changes in how individuals interacted as they aged (juvenile vs. sub-adult: $\chi^{2}(4, n=412)=171.71, p<0.001$; juvenile vs. adult: $\left.\chi^{2}(4, n=299)=213.23, p<0.001\right)$. Looking at juvenile vs. sub-adult exchanges, six of the seven dolphins changed their interaction patterns. Three individuals had a preferred sex/age category for their interactions as juveniles but not as sub-adults while the other three had no preferences as juveniles but did as sub-adults. When looking at juvenile vs. adult interactions, five of the six dolphins changed their interaction patterns. Three adults had no preferred sex/age category for their interactions as juveniles but did as adults while the other two had preferences as juveniles but not as adults. These results refute Social Status, prediction 2c (Table 1).

\section{Touch versus Rubs - Sex and Age}

Initiators engaged in rubs $(n=854,70 \%)$ more frequently than touches $(n=363,30 \%)$ as pectoral fin contact events $(N=1,217)$. Same-sex dyads exchanged more pectoral fin contacts $(n=826$, $68 \%$ ) than did DS pairs $(n=391,32 \%)$, lending support to Social Bonding, prediction 1a (Table 1). However, there was no evidence that DS pairs used touches proportionately more than rubs compared to SS pairs, $\chi^{2}(2, n=1,217)=0.102, p=0.79$; these results do not support Social Status, prediction 2a (Table 1). Males $(n=873,72 \%)$ initiated more pectoral fin contact events than did females $(n=344$, $28 \%)$ and differed in how they interacted with the other sex, $\chi^{2}(2, n=1,217)=111.564, p<0.001$. Specifically, females initiated more interactions with males so touches and rubs were high for DS interactions while males initiated more interactions with males so touches and rubs were high for SS interactions.

Touches were shorter (average $=1.22 \mathrm{~s}, \mathrm{SE}=0.05 \mathrm{~s}, n=363)$ than rubs $(M=1.88 \mathrm{~s}, S E=0.06 \mathrm{~s}$, $n=854$ ), Touch/Rub main effect: $F(1,1,177)=41.9, p<0.0001$, regardless of sex of the pair, Sex of Pair main effect: $F(1,1,177)=0.45, p=0.50$. There was no evidence that duration of touches or rubs differed by SS or DS pairs, Interaction term (Touch/Rub by Sex of Pair): $F(1,1,177)=0.07, p=0.78$. These results do not support Tension Reduction, prediction 3a (Table 1).

While DA pairs $(n=738,61 \%)$ exchanged more pectoral fin contact events overall than did pairs of the SA $(n=479,39 \%)$, rubs and touches were used in a similar proportion, $\chi^{2}(2, n=1,217)=0.43, p=$ 0.52 , which refutes Tension Reduction, prediction 3a (Table 1). Similarly, there was no significant difference in the proportionate use of rubs and touches between SA and DA pairs for either a male or female initiator, $\chi^{2}(2, n=1,217)=0.96, p=0.81$, contrary to Social Status, prediction $2 \mathrm{~b}$ and to Tension Reduction, prediction 3a (Table 1). Touches were shorter than rubs, Touch/Rub main effect: $F(1,1,177)=$ 42.0, $p<0.0001$, regardless of age of the pair, Age of Pair main effect: $F(1,1,177)=1.65, p=0.20$. Duration of rubs compared to touches did not vary whether individuals in a pair were of SA or DA, Interaction term (Touch/Rub x Age of Pair): $F(1,1,177)=0.003, p=0.95$, which also refutes Tension Reduction, prediction 3a (Table 1). 


\section{Body Part Preferences}

When considering the first-body-part contacted in SS/SA and DS/DA interactions, the first contacted body part varied by sex of the initiator, $\chi^{2}(5, n=1,217)=63.71, p<0.001$. Females initiated contact on the face (rostrum and around the eyes), peduncle, and the lateral side more in DS/DA interactions compared to SS/SA interactions. Males initiated contact more on pectoral fins, peduncle, and the lateral side in SS/SA interactions compared to DS/DA interactions, which supports Tension Reduction, prediction $3 \mathrm{c}$, for females but not for males (Table 1).

Table 4

Proportions of Different Body Parts Contacted During Non-Kin Pectoral Fin Contact Exchanges by the Rubbee and Rubber in the Role of Initiator

\begin{tabular}{|c|c|c|}
\hline \multirow[b]{2}{*}{ Body Parts } & \multicolumn{2}{|c|}{ Proportion of contacts } \\
\hline & $\begin{array}{l}\text { INI as Rubbee } \\
\quad(n=245)\end{array}$ & $\begin{array}{c}\text { INI as Rubber } \\
\quad(n=972)\end{array}$ \\
\hline $\begin{array}{l}\text { PF-F } \\
\text { PF-O } \\
\text { PF-T } \\
\text { PF-H } \\
\text { PF-E }\end{array}$ & $\begin{array}{l}\mathbf{0 . 4 6 5} \\
0.249 \\
0.184 \\
0.061 \\
0.041\end{array}$ & $\begin{array}{l}0.144 \\
\mathbf{0 . 3 8 1} \\
\mathbf{0 . 3 3 8} \\
0.070 \\
0.067\end{array}$ \\
\hline “Other" Body Parts (PF-O) & $\begin{array}{l}\text { INI as Rubbee } \\
\quad(n=61)\end{array}$ & $\begin{array}{c}\text { INI as Rubber } \\
\quad(n=370)\end{array}$ \\
\hline $\begin{array}{c}\text { Belly } \\
\text { dorsal fin } \\
\text { Peduncle } \\
\text { Fluke } \\
\text { Keel } \\
\text { Genitals }\end{array}$ & $\begin{array}{l}0.246 \\
0.213 \\
0.180 \\
\mathbf{0 . 1 8 0} \\
0.148 \\
0.033\end{array}$ & $\begin{array}{l}0.314 \\
0.197 \\
\mathbf{0 . 3 1 6} \\
0.033 \\
0.108 \\
0.032 \\
\end{array}$ \\
\hline
\end{tabular}

Note. Abbreviations include: $\mathrm{INI}=$ initiator; $\mathrm{PF}=$ pectoral fin; $\mathrm{F}=$ face; $\mathrm{O}=$ other body parts; $\mathrm{T}=$ torso; $\mathrm{H}=$ pectoral fin; $\mathrm{E}=$ back. Body parts that were contacted more than expected are in bold. See Figure 1 for body part reference.

The body part contacted differed when the initiator was a rubbee or a rubber, $\chi^{2}(5, n=1,217)=$ $124, p<0.0001$ (Table 4), specifically, the body part contacted most when the initiator was a rubbee was the face $(46.5 \%)$, whereas when the initiator was a rubber, the peduncle, flukes, and dorsal fin (collectively comprised as "other" body parts) and the torso were the most contacted parts $(38.1 \%$ and $33.8 \%$, respectively), which would refute the Tension Reduction Hypothesis, prediction $3 \mathrm{c}$ (Table 1). The pattern of contact of "other" body parts also differed when the initiator was a rubber or a rubbee, $\chi^{2}(6$, $n=441)=26.3, p<0.001$. The initiator as a rubber contacted the receiver's peduncle approximately twice as often as when the initiator was a rubbee; the initiator as a rubbee contacted the receiver's fluke about six times more than when the initiator was a rubber (Table 4), which would refute the Tension Reduction Hypothesis, prediction 3c (Table 1).

The overall contact pattern for body parts when the initiator was a rubber or rubbee did not vary by sex of the initiator, $\chi^{2}(5, n=1,217)=8.4, p=0.50$, or by age class (rubbee pattern: $\chi^{2}(5, n=245)=$ 13.9, $p=0.30$; rubber pattern: $\left.\chi^{2}(5, n=972)=10.9, p=0.54\right)$. However, the pattern of contact of "other" body parts when the initiator was a rubber varied by age, $\chi^{2}(6, n=370)=26.58, p=0.031$ (Table 5) but not as a rubbee, $\chi^{2}(6, n=61)=17.47, p=0.30$. Adults as rubbers contacted the fluke and dorsal fin more and calves as rubbers contacted the keel more than juveniles and sub-adults when they initiated contact as rubbers (Table 5). These results suggest that pectoral fin contact by rubbers does not support the Tension Reduction Hypothesis, prediction 3c (Table 1), regardless of the recipient's sex and age class. More information regarding the use of pectoral fin contact by initiators as rubbees is required to clarify how rubbees use this tactile behavior to reduce tension socially, and to confirm whether the Tension Reduction Hypothesis is refuted or supported. 
Table 5

Proportions of "Other" Body Parts Contacted During Non-Kin Pectoral Fin Contact Exchanges by the Rubbee and Rubber in the Role of Initiator by Age Class

\begin{tabular}{|c|c|c|c|c|c|c|c|c|}
\hline \multirow{3}{*}{$\begin{array}{c}\text { "Other" } \\
\text { Body Parts }\end{array}$} & \multicolumn{8}{|c|}{ Proportions of contacts } \\
\hline & \multicolumn{4}{|c|}{ INI as Rubbee } & \multicolumn{4}{|c|}{ INI as Rubber } \\
\hline & $\begin{array}{c}\text { Calf } \\
(n=10)\end{array}$ & $\begin{array}{c}\text { Juvenile } \\
(n=24)\end{array}$ & $\begin{array}{l}\text { Subadult } \\
(n=12)\end{array}$ & $\begin{array}{c}\text { Adult } \\
(n=15)\end{array}$ & $\begin{array}{c}\text { Calf } \\
(n=90)\end{array}$ & $\begin{array}{l}\text { Juvenile } \\
(n=135)\end{array}$ & $\begin{array}{c}\text { Subadult } \\
(n=92)\end{array}$ & $\begin{array}{c}\text { Adult } \\
(n=53)\end{array}$ \\
\hline belly & 0.4 & 0.083 & 0.5 & 0.2 & 0.233 & 0.341 & 0.380 & 0.264 \\
\hline dorsal fin & 0.1 & 0.208 & 0.167 & 0.333 & 0.178 & 0.163 & 0.207 & 0.302 \\
\hline peduncle & 0.2 & 0.25 & 0.083 & 0.133 & 0.344 & 0.348 & 0.272 & 0.264 \\
\hline fluke & 0.1 & 0.292 & 0.167 & 0.071 & 0.011 & 0.022 & 0.033 & 0.094 \\
\hline keel & 0.1 & 0.125 & 0.083 & 0.067 & 0.178 & 0.089 & 0.098 & 0.057 \\
\hline genitals & 0.1 & 0.042 & 0 & 0 & 0.056 & 0.037 & 0.011 & 0.019 \\
\hline
\end{tabular}

Note. INI = initiator. Body parts that were contacted more than expected are in bold. See Figure 1 for body part reference.

\section{Discussion}

For bottlenose dolphins in this study, the exchange of pectoral fin contact between individuals is supported as a tool for social bonding within same-sex, same-aged dyads, especially within young male pairs. Pectoral fin contact is suggested as a behavioral tool, used singly or possibly in association with other affiliative behaviors such as synchronous swimming, as dolphins establish and strengthen or maintain relationships that could last for years, if not their entire lives. The three hypotheses examined in this study (Social Bonding, Social Status, and Tension Reduction; Table 1) are not mutually exclusive, though more support was documented for social bonding as an overarching explanation than for social status or tension reduction in the exchange of pectoral fin contact within dyads in this group. Results from this study confirm that pectoral fin contact is more frequent between SS/SA dyads, between non-kin as compared with kin (through the maternal line), and, though presented in a relatively smaller sample size, immediate reciprocity is more frequent between SS/SA than DS/DA pairs. These results support the Social Bonding Hypothesis as a functional explanation for pectoral fin contact exchanges among dolphins. Even though dolphins of differing ages did initiate pectoral fin contacts with peers, there was no clear-cut pattern of either younger or older dolphins acting as the primary initiator. Also, pectoral fin contact was immediately reciprocal, even if in low numbers. Thus, the Social Status Hypothesis would seem to be refuted. Support for this assessment is gleaned from the literature confirming that dolphins typically do not exhibit linear dominance hierarchies, but rather reside in a complex web of relationships of varying strengths (Lusseau, 2003; Lusseau et al., 2006). Indeed, even for this dolphin study group, dominance as an explanation for male-male social interactions was recently refuted by Acosta (2015).

When assessing the Tension Reduction Hypothesis as a functional explanation for pectoral fin contact exchanges, less support is observed from our data: duration of contacts does not vary by sex or age and static touches were observed with similar frequency to rubs. Neither the rubber nor rubbee initiated more contacts than the other. Also, as for the Social Status Hypothesis, some dolphins in this group did share contacts reciprocally. That said, the body part contacted suggests that in some instances, pectoral fin contact could function to reduce tension between individuals. It is possible that a rubbee would present a sensitive body part (e.g., face, melon) to a rubber when initiating an interaction. This might diffuse a situation from escalating from mild agonism to outright aggression, especially if both participants understood presentation of a sensitive body part as risky for the rubbee. One might consider this type of action to be a form of dolphin submission; however, it is not possible in the present study to rule out the alternative consideration of individual preference for a body part or lack of accuracy in presenting a body part to a peer (especially for younger individuals). A third alternative could simply be that the rubbee would prefer a pectoral fin rub from a partner rather than self-rubbing against the coral or sand in the environment, though this explanation seems not to be the case during this study. 
Conflict and reconciliation have been studied rarely in dolphins with only two studies available in the literature (Tamaki, Morisaka, \& Taki, 2006; Weaver, 2003). Whereas Weaver focused on gentle body contacts exhibited post conflict as evidence of tension reduction between individuals, Tamaki et al. examined pectoral fin contacts (i.e., flipper rubbing) used during post-conflict periods and control periods to determine whether dolphins use this behavior to reduce conflicts. With their limited sample size, Tamaki et al.'s results suggested that flipper rubbing might contribute to restoration of associations or reduce conflicts for specific sex/age groups. Tamaki et al. found that post conflict rubbing reduced the probability of another conflict in that latency to the next aggressive behavior was longer when either individual engaged in flipper rubbing.

During this study, "other" body parts contacted included the belly/ventral side, dorsal fin, keel and fluke. Previous studies of pectoral fin contact exchanges in this study group and two wild dolphin study groups (Dudzinski, 1998; Dudzinski et al., 2009, 2010) suggested that the contacts varied in function depending on body part contacted. The peduncle was suggested as functioning as a request location, depending on context; adult dolphins' pectoral fin contacted the lateral side (torso) of juveniles when the latter were exhibiting agitated, energetic actions (Dudzinski, 1998). Additionally, it is interesting to note that juvenile dolphins when in the role of initiator as rubber contacted the peduncle more than other body parts; the peduncle has been previously identified as functioning as a solicitation when contacted by a pectoral fin (Dudzinski, 1998, Dudzinski et al., 2009, 2010). Thus, it would seem that these results suggest that the Tension Reduction and Social Bonding Hypotheses are not mutually exclusive but depend on context for the contact exchange as well as the body part being contacted.

Dolphins are long-lived social mammals residing in a fluid society characterized by fission-fusion dynamics that require an understanding of the signals and behaviors that regulate their social activity. Communicative signals are context dependent and often expressed in concert with other behaviors, postures or vocalizations (e.g., Evans-Wilent \& Dudzinski, 2013). How pectoral fin contacts are shared between individuals within a dyad changed as those individuals aged and also depended on their sex; there are seemingly different roles for males and females within this promiscuous society. In our study, some dolphins had preferred sex/age categories for their interactions when younger whereas others exhibited preferred sex/age categories after maturing. The majority of individuals changed their preferences, supporting developmental changes for the role of pectoral fin contact as a social tool to establish and maintain bonds between individuals.

Alliance formation, the benefits and costs of first- and second- order alliance formation, and the social and cognitive currency required to form such partnerships has been extensively studied by Connor and colleagues among bottlenose dolphins in Shark Bay, Australia (Connor, 1992; Connor et al., 1992; Connor, Mann et al., 2006; Connor, Smolker et al., 2006). Connor and Krützen (2015) summarized the chronological understanding of dolphin social alliances setting our increasing knowledge within the context of large brain social evolution. Some alliances can vary in duration, size and stability, though second order alliances may persist for 20 years or more. While the benefits of alliance formation, the multiple levels for potential alliances and the currency required to manage one's alliances have been well documented, less attention has been given to how these alliances might first be established. In our study, young male bottlenose dolphins share significantly more pectoral fin contact with young non-kin males than with other age groups, and male dyads share more pectoral fin contact than do female dyads. These results suggest that at least these young male bottlenose dolphins seem to use pectoral fin contact to establish relationships with preferred peers and then to manage those relationships as they develop, both socially and sexually. Pectoral fin contact exchanges would seem to facilitate a tactile exchange of information that might be required to invite a peer to establish a relationship. Shared, reciprocal pectoral fin contacts could reinforce the development of a relationship between individuals.

The younger males in this group are fluid in the amount of time spent with other young males as well as in the amount of pectoral fin contacts shared with same-sex, same-aged peers. During observations collected after this study, three pairs of older males, each of whom we included in this study at younger ages (calf through adult), presented strong friendships identified by the amount of time spent together and the amount pectoral fin contacts exchanged (Dudzinski, unpublished data, 2012 - 2016). 
These adult male dyads are each observed together during sessions when all dolphins are together. These dolphins seem to prefer to spend time with their partner and can, at times, seem reluctant (though not unwilling) to separate when asked to coordinate programs (e.g., dives off the reef with human scuba divers) with a different male partner (Teri Bolton, personal communication, 2014). Our observations of the relationships formed and expressed via behavioral exchange and time spent together support the likely existence of alliances formed among these males, which seems similar to what has been documented by Connor (e.g., Connor et al., 1992; Connor \& Krützen, 2015) and Wells (Wells, 1991; Wells et al., 1987) for wild bottlenose dolphins at Shark and Sarasota Bays, respectively, and more recently for this dolphin study group (Acosta, 2015; Harvey, 2015; Harvey, Dudzinski, \& Kuczaj, 2017).

Young female bottlenose dolphins in this group are less consistent in selection of a partner's sex/age with whom they share pectoral fin contact; however, once these females reach sexual and social maturity, they share pectoral fin contact mostly with other adult females. Differences were found in this study in how males and females shared pectoral fin contacts, both within and between sexes. Animal societies reflect relationships formed between pairs; how relationship patterns are distributed across a population defines its social organization. Affiliative behaviors are often exchanged characteristically to define individual relationships within a group. Touch has a significant role in social development and is an important display of affiliation and social bonding (Zahavi, 1977). Tactile behaviors are used to establish, maintain, strengthen, navigate, and repair social bonds within a wide range of social mammals. Adult female spotted hyenas (Crocuta crocuta) use affiliative greeting behaviors (e.g., nuzzling, rubbing against, sniffing, friendly approaches, etc.) spontaneously and rarely in response to aggression, which reinforced social bonds and promoted cooperation among group members (Smith et al., 2011). Carter et al. (2013) confirmed that female giraffes showed both preferential and avoidance relationships that were minimally related to spatial overlap and kinship; giraffes, like dolphins, have structured social patterns and seem to express individual choice. Frere et al. (2010) examined home range overlap with kinship in female associations among bottlenose dolphins identifying preferred associations for some dyads and avoidance for others even with minimal or $100 \%$ home range overlap, respectively.

It is clear for a variety of species that individual preference exists between pairs in many relationships (e.g., chimpanzees, Foerster et al., 2015; mountain goats, Oreamnos americanus, Godde, Côte, \& Réale, 2015; bottlenose dolphins, Frère et al., 2011; Wiszniewski, Allen, \& Möller, 2009; Wisziewski, Lusseau, \& Möller, 2010), and that these relationships likely form before the individuals are sexually and socially mature. Within this study, differences were found between the sexes for juveniles, sub-adults, and adults with respect to non-kin pectoral fin contacts. Juvenile females initiated pectoral fin contacts with different-sex and different-aged individuals much more than with other young females while juvenile male dolphins shared the majority of their contacts with other males. Sub-adult males continued to interact with males, though of a different age, whereas adults, whether male or female, tended to share pectoral fin contacts with other adults. Partner preference is evident in these results and is supported by previous studies of pectoral fin contact in this group (Dudzinski et al., 2010) and in other groups (Dudzinski et al., 2009, 2013). Looking at a subset of these data from 2010, Harvey (2015) examined association patterns via proximity measures for each possible dyad in the study group. These researchers found similar patterns to previous studies on bottlenose dolphins: mother-calf dyads shared the highest coefficients of association, followed by male-male, female-female, and male-female dyads (Harvey, 2015; Harvey et al., 2017).

Even though immediate reciprocity was not observed as frequently as we had expected, there were trends to suggest that reciprocal exchanges of pectoral fin contact could have a function in this group. Patterns of immediate reciprocity were different within and between the sexes with individuals having different sex and age preferences for which dolphin they shared IR contact. Still, male dolphins shared more immediate reciprocity contact with other males while females shared with both sexes nearly at the same rate. And, when patterns were found, identified individuals more often had similar patterns in their contacts and IR exchanges than not. These observations provide support for social bonding and tension reduction, though not for social status as an explanation for patterns in pectoral fin contact exchanges. 
Sex and age are significant factors in the exchange of pectoral fin contacts between non-kin dolphin dyads. Males shared more pectoral fin contacts with other males as juveniles and as adults. Males showed no difference in the number of touches versus rubs as pectoral fin contacts with other males. Whether in the role of initiator as rubber or initiator as rubbee, male dolphins again preferred other males while female dolphins generally did not.

\section{Conclusions}

Pectoral fin contact exchanges within dyads seem not to be impacted by potential hierarchical structure in bottlenose dolphin society. Our focus in this study was on pectoral fin contact exchanges as events separate from potential overlap with other cues (e.g., postures, behaviors, vocalizations), which might modify the function of a pectoral fin contact. Our results support the notion that dolphins, especially male dolphins, use pectoral fin contact as one tool for social bonding to establish, maintain and manage their inter-individual relationships. The observed differences between males and females in their use of pectoral fin contact as well as the different body parts used by initiators in different roles (rubber vs. rubbee) also support the idea that there are functional differences between the sex-age dyads in how this contact behavior is used. It is also likely that the exchange of pectoral fin contact is developed and refined as individuals age, mature socially, and establish their place within a fission-fusion society.

\section{Acknowledgements}

Financial support for longitudinal data collection has been provided continuously by the Dolphin Communication Project (DCP). Mystic Aquarium provided financial support towards data collection during 2004 - 2006. The Galindo Family and Anthony's Key Resort (AKR) provided logistical support that included lodging, food, and access to the dolphins during all years of study at the Roatan Institute for Marine Sciences (RIMS). DCP-organized eco-tours brought volunteers to AKR to assist with additional funding for data collection. Eldon Bolton, RIMS Director, provided access to records for the dolphins under his supervision. Teri Bolton and the training team of RIMS provided much insight and discussion during and after observation sessions of the dolphins. Numerous interns and volunteers assisted with processing video data, special thanks to A. Levengood, N. Danaher-Garcia, B. McIntosh, J. Evans-Wilent, and W. Greene. K. Melillo-Sweeting, J. Gregg, H. Hill, J. Bruck, R. Makecha, and D. Rugg reviewed early drafts of this manuscript. D. Rugg provided valuable suggestions on statistical analyses. Many thanks to A. Bowles and three anonymous reviewers for their comments and suggestions, which greatly improved this paper. Any use of trade, product, or firm names is for descriptive purposes only and does not imply endorsement by the U.S. Government. This paper represents contribution \#118 of the Dolphin Communication Project.

\section{References}

Acosta, N. B. (2015). Same-sex socio-sexual interactions among a group of captive bottlenose dolphins (Tursiops truncatus). Master's Thesis, The University of Southern Mississippi, Hattiesburg, MS.

Altmann, J. (1974). Observational study of behavior: Sampling methods. Behaviour, 49, 227-267.

Anderson, S. (1969). Epimeletic behavior in a captive harbor porpoise, Phocaena phocaena. In G. Pilleri (Ed.), Investigations on cetacean, Vol. 1 (pp. 203-205). Berne, Switzerland: Braine Anatomy Institute.

Aureli, F., Schaffner, C. M., Boesch, C., Bearder, S. K., Call, J., Chapman, C. A., ...van Schaik, C. P. (2008). Fission-fusion dynamics: New research frameworks. Current Anthropology, 49, 627-654.

Bruck, J. (2013). Decades-long social memory in bottlenose dolphins. Proceedings of the Royal Society of London B: Biological Sciences, 280. doi:10.1098/rspb.2013.1726

Cairns, S. J., \& Schwager, S. J. (1987). A comparison of association indices. Animal Behaviour, 35, 1454-1469. 
Carter, K. D., Brand, R., Carter, J. K., Shorrocks, B., \& Goldizen, A. W. (2013). Social networks, long-term associations and age-related sociability of wild giraffes. Animal Behaviour, 86, 901-910.

Connor, R. C. (1992). Dolphin alliances and coalitions. In: A. H. Harcourt. \& F. de Waal (Eds.), Coalitions and alliances in humans and other animals (pp. 415-443). Oxford, UK: Oxford University Press.

Connor, R. C. (1995). Altruism among non-relatives: Alternatives to the 'Prisoner's Dilemma.' Trends in Ecology and Evolution, 10, 84-86.

Connor, R. C., \& Krützen, M. (2015). Male dolphin alliances in Shark Bay: Changing perspectives in a 30-year study. Animal Behaviour, 103, 223-235.

Connor, R. C., \& Mann, J. (2006). Social cognition in the wild: Machiavellian dolphins? In: S. Hurley \& M. Nudds (Eds.), Rational animals? (pp. 329-367). Oxford, UK: Oxford University Press.

Connor, R. C., Mann, J., \& Watson-Capps, J. (2006). A sex-specific affiliative contact behavior in Indian Ocean bottlenose dolphins, Tursiops sp. Ethology, 112, 631-638.

Connor, R. C., \& Norris, K. S. (1982). Are dolphins reciprocal altruists? American Naturalist, 119, 358-374.

Connor, R. C., Smolker, R., \& Bejder, L. (2006). Synchrony, social behaviour and alliance affiliation in Indian Ocean bottlenose dolphins, Tursiops aduncus. Animal Behaviour, 72, 1371-1378.

Connor, R. C., Smolker, R. A., \& Richards, A. F. (1992). Two levels of alliance formation among male bottlenose dolphins (Tursiops sp.). Proceedings of the National Academy of Sciences of the United States of America, 89, 987-990.

de Waal, F. (1989). Chimpanzee politics. Baltimore, MD: The Johns Hopkins University Press.

Dudzinski, K. M. (1996). Communication and behavior in the Atlantic spotted dolphins (Stenella frontalis): Relationships between vocal and behavioral activities. (Unpublished doctoral dissertation). Texas A\&M University, College Station, TX.

Dudzinski, K. M. (1998). Contact behavior and signal exchange among Atlantic spotted dolphins (Stenella frontalis). Aquatic Mammals, 24, 129-142.

Dudzinski, K. M. (2010). Overlap between information gained from complimentary and comparative studies of captive and wild dolphin communication. International Journal of Comparative Psychology, 23, 566-586.

Dudzinski, K. M., Clark, C. W., \& Würsig, B. (1995). A mobile video/acoustic system for simultaneous recording underwater recording of dolphin interactions. Aquatic Mammals, 21, 187-193.

Dudzinski, K. M., Danaher-Garcia, N., \& Gregg, J. D. (2013). Pectoral fin contact between dolphin dyads at Zoo Duisburg, with comparison to other dolphin study populations. Aquatic Mammals, 39, 335-343.

Dudzinski, K. M., Gregg, J. D., Melillo-Sweeting, K., Levengood, A., Seay, B., \& Kuczaj II, S. A. (2012). Tactile contact exchanges between dolphins: Self-rubbing versus inter-individual contact in three species from three geographies. International Journal of Comparative Psychology - Special Symposium Issue, 25, 21-43.

Dudzinski, K. M., Gregg, J. D., Paulos, R. D., \& Kuczaj, S. A. (2010). A comparison of pectoral fin contact behaviour for three distinct dolphin populations. Behavioural Processes, 84, 559-567.

Dudzinski, K. M., Gregg, J. D., Ribic, C. A., \& Kuczaj, S. A. (2009). A comparison of pectoral fin contact between two different wild dolphin populations. Behavioural Processes, 80, 182-190.

Dudzinski, K. M., Sakai, M., Masaki, K., Kogi, K., Hishii, T., \& Kurimoto, M. (2003). Behavioural observations of bottlenose dolphins towards two dead conspecifics. Aquatic Mammals, 29, 108-116.

Elliser, C. R., \& Herzing, D. L. (2014). Long-term social structure of a resident community of Atlantic spotted dolphins, Stenella frontalis, in the Bahamas 1991-2002. Marine Mammal Science, 30, 308-328.

Evans-Wilent, J., \& Dudzinski, K. M. (2013). Vocalizations associated with pectoral fin contact in bottlenose dolphins (Tursiops truncatus). Behavioural Processes, 100, 74-81.

Fishlock, V., \& Lee, P. C. (2013). Forest elephants: Fission-fusion and social arenas. Animal Behaviour, 85, 357363.

Foerster, S., McLellan, K., Schroepfer-Walker, K., Murray, C. M., Krupenye, C., ...Pusey, A. E. (2015). Social bonds in the dispersing sex: Partner preferences among adult female chimpanzees. Animal Behaviour, 105, $139-152$.

Fraser, O. N., \& Bugnyar, T. (2010). The quality of social relationships in ravens. Animal Behaviour, 79, 927-933. doi: 10.1016/j.anbehav.2010.01.008

Fraser, O. N., Schino, G., \& Aureli, F. (2008). Components of relationship quality in chimpanzees. Ethology, 114, 834-843. doi: 10.1111/j.1439-0310.2008.01527.x

Garson, G. I., \& Moser, E. B. (1995). Aggregation and the Pearson Chi-square statistic for homogeneous proportions and distributions in ecology. Ecology, 76, 2258-2269.

Godde, S., Côte, S. D., \& Réale, D. (2015). Female mountain goats, Oreamnos americanus, associate according to kinship and reproductive status. Animal Behaviour, 108, 101-107. 
Goodall, J. (1986). The chimpanzees of Gombe: Patterns of behavior. Cambridge, MA: The Belknap Press of Harvard University.

Gregg, J. D., Dudzinski, K. M., \& Smith, H. V. (2007). Do dolphins eavesdrop on the echolocation signals of conspecifics? International Journal of Comparative Psychology, 20, 65-88.

Harvey, B. N. (2015). The nature of social relationships in bottlenose dolphins (Tursiops truncatus): Associations and the role of affiliative, agonistic, and socio-sexual behaviors. (Unpublished master's thesis). University of Southern Mississippi, Hattiesburg, MS.

Harvey, B. S., Dudzinski, K. M., \& Kuczaj, S. A. (2017). Associations and the role of affiliative, agonistic, and socio-sexual behaviors among bottlenose dolphins (Tursiops truncatus). Behavioural Processes, 135, 145156.

Herzing, D. (1997). The natural history of free-ranging Atlantic spotted dolphins (Stenella frontalis): Age classes, color phases, and female reproduction. Marine Mammal Science, 13, 576-595.

Herzing, D. L., \& Brunnick, B. J. (1997). Coefficients of association of reproductively active female Atlantic spotted dolphins, Stenella frontalis. Aquatic Mammals, 23, 155-162.

Janik, V. M., Sayigh, L. S., \& Wells, R. S. (2006). Signature whistle shape conveys identity information to bottlenose dolphins. Proceedings of the National Academy of Sciences of the United States of America, 103, 8293-8297.

Johnson, C. M., \& Moewe, K. (1999). Pectoral fin preference during contact in Commerson's dolphins (Cephalorhynchus commersonii). Aquatic Mammals, 25, 73-77.

King, S. L., Harley, H. E., \& Janik, V. M. (2014). The role of signature whistle matching in bottlenose dolphins, Tursiops truncatus. Animal Behaviour, 96, 79-86.

Kogi, K., Hishi, T., Imamura, A., Iwatani, T., \& Dudzinski, K. M. (2004). Demographic parameters of Indo-Pacific bottlenose dolphins (Tursiops aduncus) around Mikura Island, Japan. Marine Mammal Science, 20, 510526.

Kummer, H. (1978). On the value of social relationships to non-human primates: a heuristic scheme. Social Science Information, 17, 687-705.

Lloyd, C. J. (1999). Statistical analysis of categorical data. New York, NY: Wiley and Sons.

Lusseau, D. (2003). The emergent properties of a dolphin social network. Proceedings of the Royal Society of London B (Biology Letters) 03BL0149.S1-S3. doi: 10.1098/rsbl.2003.0057

Lusseau, D., Wilson, B., Hammond, P. S., Grellier, K., Durban, J. W., Parsons, K. M., ...Thompson, P. A. (2006). Quantifying the influence of sociality on population structure in bottlenose dolphins. Journal of Animal Ecology, 75, 14-24.

Majolo, B., Schino, G., \& Aureli, F. (2012). The relative prevalence of direct, indirect and generalized reciprocity in macaque grooming exchanges. Animal Behaviour, 83, 763-771. doi: 10.1016/j.anbehav.2011.12.026

Mann, J. (1999). Behavioral sampling for cetaceans: A review and critique. Marine Mammal Science, 15, $102-122$.

Mann, J., \& Smuts, B. (1998). Behavioral development in wild bottlenose dolphin newborns (Tursiops sp.). Behaviour, 136, 529-566.

Massen, J. J. M., Sterck, E. H. M., \& de Vos, H. (2010). Close social associations in animals and humans: Functions and mechanisms of friendship. Behaviour, 147, 1379-1412.

Matoba, T., Kutsukake, N., \& Hasegawa, T. (2013). Head rubbing and licking reinforce social bonds in a group of captive African lions, Panthera leo. Plos ONE, 8, e73044. doi: 10.1371/journal.pone.0073044

Newton-Fisher, N. E., \& Lee, P. C. (2011). Grooming reciprocity in wild male chimpanzees. Animal Behaviour, 81, 439-446. doi: 10.1016/j.anbehav.2010.11.015

Östman, J. (1991). Changes in aggressive and sexual behavior between two male bottlenose dolphins (Tursiops truncatus) in a captive colony. In K. Pryor \& K. S. Norris (Eds.), Dolphin societies: Discoveries and puzzles (pp. 305-317). Berkeley, CA: University of California Press.

Overstrom, N. A. (1983). Association between burst-pulse sounds and aggressive behavior in captive Atlantic bottlenosed dolphins (Tursiops truncatus). Zoo Biology, 2, 93-103.

Paulos, R. D., Dudzinski, K., \& Kuczaj, S. (2007). The role of touch in select social interactions of Atlantic spotted dolphin (Stenella frontalis) and Indo-Pacific bottlenose dolphin (Tursiops aduncus). Journal of Ethology, 26, 153-164.

Pinheiro, J. C., \& Bates, D. M. (2009). Mixed-effects models in S and S-Plus. New York, NY: Springer.

Ridgway, S. H., \& Carder, D. A. (1993). Features of dolphin skin with potential hydrodynamic importance. IEEE Engineering in Medicine and Biology, Sept., 83-88. 
Rossbach, K. A., \& Herzing, D. L. (1999). Inshore and offshore bottlenose dolphin (Tursiops truncatus) communities distinguished by association patterns near Grand Bahama Island, Bahamas. Canadian Journal of Zoology, 77, 581-592.

Rugg, D. J. (2003). TableSim-A program for analysis of small-sample categorical data. General Technical Report No. NC-232. St. Paul, MN: U.S. Department of Agriculture, Forest Service, North Central Research Station.

Sakai, M., Hishii, T., Takeda, S., \& Kohshima, S. (2006a). Flipper rubbing behaviors in wild bottlenose dolphins (Tursiops aduncus). Marine Mammal Science, 22, 966-978.

Sakai, M., Hishii, T., Takeda, S., \& Kohshima, S. (2006b). Laterality of flipper rubbing behaviour in wild bottlenose dolphins (Tursiops aduncus): Caused by asymmetry of eye use? Behavioural Brain Research, 170, 204210.

Samuels, A., \& Gifford, T. (1997). A quantitative assessment of dominance relations among bottlenose dolphins. Marine Mammal Science, 13, 70-99.

Sauvé, C. C., Beauplet, G., Hammill, M. O., \& Charrier, I. (2015). Mother-pup vocal recognition in harbour seals: Influence of maternal behavior, pup voice and habitat sound properties. Animal Behaviour, 105, 108-120.

Sayigh, L. S., Esch, H. C., Wells, R. S., \& Janik, V. M. (2007). Facts about signature whistles of bottlenose dolphins, Tursiops truncatus. Animal Behaviour, 74, 1631-1642.

Simard, P., \& Gowans, S. (2004). Two calves in echelon: An alloparental association in Atlantic white-sided dolphins (Lagenorhynchus acutus)? Aquatic Mammals, 30, 330-334.

Smith, J. E., Powning, K. S., Dawes, S. E., Estrada, J. R., Hopper, A. L., ...Holekamp, K. E. (2011). Greetings promote cooperation and reinforce social bonds among spotted hyaenas. Animal Behaviour, 81, 401-415.

Smolker, R. A., Richards, A. F., Connor, R. C., \& Pepper, J. W. (1992). Sex differences in patterns of association among Indian Ocean bottlenose dolphins. Behaviour, 23, 38-69.

Smuts, B. B., Cheney, D. L., Seyfarth, R. M., Wrangham, R. W., \& Struhsaker, T. T. (1987). Primate societies. Chicago, IL: The University of Chicago Press.

Tamaki, N., Morisaka, T., \& Taki, M. (2006). Does body contact contribute towards repairing relationships? The association between flipper-rubbing and aggressive behavior in captive bottlenose dolphins. Behavioral Processes, 73, 209-215.

Tavolga, M. C., \& Essapian, F. S. (1957). The behavior of the bottle-nosed dolphin Tursiops truncatus: Mating, pregnancy, parturition and mother-infant behavior. Zoologica, 421, 11-31.

Trimble, M., \& Charrier, I. (2011). Individuality in South American sea lion (Otaria flavescens) mother-pup vocalizations: Implications of ecological constraints and geographical variations? Mammalian Biology, 76, 208-216.

Trivers, R. (1971). The evolution of reciprocal altruism. Quarterly Review of Biology, 56, 35-57.

Trivers, R. (1985). Social evolution. Menlo Park, CA: The Benjamin/Cummings Publishing Company, Inc.

Wakefield, M. L. (2013). Social dynamics among females and their influence on social structure in an East African chimpanzee community. Animal Behaviour, 85, 1303-1313.

Weaver, A. (2003). Conflict and reconciliation in captive bottlenose dolphins, Tursiops truncatus. Marine Mammal Science, 19, 836-846.

Wells, R. S. (1991). The role of long-term study in understanding the social structure of a bottlenose dolphin community. In K. S. Norris, B. Würsig, R. Wells, \& M. Würsig (Eds.), Dolphin societies: Discoveries and puzzles (pp. 199-225). Berkeley, CA: University of California Press.

Wells, R. S., Scott, M. D., \& Irvine, A. B. (1987). The social structure of free-ranging bottlenose dolphins. In H. H. Genoways (Ed.), Current Mammalogy, Vol. 1 (pp. 247-305). New York, NY: Plenum Press.

Whitehead, H., \& Weilgart, L. (2000). The sperm whale: Social females and roving males. In S. Mann, R. C. Conner, R. L. Tyack, \& H. Whitehead (Eds), Cetacean societies (pp. 802-813). Chicago, IL: The University of Chicago Press.

Wilson, D. R., Goble, A. R., Boutin, S., Humphries, M. M., Coltman, D. W., Gorrel, J. C., ...McAdam, A. G. (2015). Red squirrels use territorial vocalizations for kin discrimination. Animal Behaviour, 107, 79-85.

Wiszniewski, J., Allen, S. J., \& Möller, L. M. (2009). Social cohesion in a hierarchically structured embayment population of Indo-Pacific bottlenose dolphins. Animal Behaviour, 77, 1449-1457.

Wiszniewski, J., Lusseau, D., \& Möller, L. M. (2010). Female bisexual kinship ties maintain social cohesion in a dolphin network. Animal Behaviour, 80, 895-904.

Young, J. K., González-Suárez, M., \& Gerber, L. R. (2008). Determinants of agonistic interactions in California sealions. Behaviour, 145, 1797-1810.

Zahavi, A. (1977). The testing of a bond. Animal Behaviour, 25, 246-247. 